\title{
The function of a university in South Africa: Part 1
}

AUTHOR:

Sean Archer $^{1}$

\section{AFFILIATION:}

'Department of Economics, University of Cape Town,

Cape Town, South Africa

\section{CORRESPONDENCE TO:} Sean Archer

EMAIL:

sean.archer@uct.ac.za

\section{KEYWORDS:}

higher education institution; first-order roles; secondary roles

\section{HOW TO CITE:}

Archer S. The function of a university in South Africa: Part 1. S Afr J Sci. 2017;113(5/6), Art. \#a0190, 6 pages. http://dx.doi. org/10.17159/sajs.2017/a0190

(C) 2017. The Author(s). Published under a Creative Commons Attribution Licence.
South African universities are under pressure to alter their institutional cultures and policies in order to provide compensation for the neglect of black academic staff and students during our apartheid past. This redress is interpreted by pressure groups and policymakers to entail giving priority to rectification goals within existing universities. What is ignored is the question of whether the first-order functions of every South African university - which are research and teaching - will be compromised. Elevating a second-order function like redress above what have historically been the defining features of a university for more than a thousand years, has probable destructive consequences overlooked by academic and administrative insiders and policymakers. But when viewed historically, educational compensation is a recent phenomenon, arising within the last century. Because of the large scale involved in the South African case, these pressures on local universities are an extreme version of what is locally called 'a concern with redress or social justice'. As such, these institutions are being pushed into a major historical experiment. Most important, it is a process without the needed research backing. So this lack of precedence and research must be accorded much greater recognition within South African universities themselves than is evident so far. If our institutions are facing an existential crisis, it must be acknowledged openly. If such an outcome remains an afterthought, recognised only once it is here, then the damage in many spheres of our national life will be extremely high.

$$
\text { 'It's a poor sort of memory that only works backwards' the Queen remarked. }
$$
Lewis Carroll, Through the Looking Glass

\section{Introduction}

A number of misconceptions shape thinking about South Africa's universities in the post-apartheid era. Such misconceived ideas may be understandable in politicians but one wonders why these ideas appear also in the reform programmes urged by education policymakers, their advisers, and even by certain professional educationists.

The argument of this essay is straightforward. The core or first-order functions of a university system are more important than its second-order functions, like the pursuit of equality or redress. If the first-order functions are not fulfilled then there is nothing to re-distribute to a wider segment of the population in a given country and a given higher education system. Thus, secondary functions cannot be conceived as continuous with the core functions, but rather as subsequent and dependent. This conceptual distinction is not appreciated in a great deal of South African discussion about university reform in the post-apartheid period.

The title of this essay anticipates some definite and complete answer, which is more than can be provided. The subject matter is complex and widely ramifying so it cannot be wholly accounted for in a short treatment. But the urgency of the questions it raises makes an attempt necessary even if partial in its nature.

In the long run, if it should turn out that South Africa's universities make the transition successfully to the new set of functions demanded by government and by many others, that outcome will be gratifying but also surprising. No one wants South African higher education to fail because new and unique burdens are being placed on the existing institutions. But equally no one can tell whether the universities will endure the imposed changes without failing to meet as well their first-order or systemic functions in society, polity and economy.

Because terminology is important it needs stating that the labels chosen for these two kinds of university functions, core and supplementary, are potentially divisive. The concern with inequality in many, perhaps most, countries at the present time has heightened the expectation that a key institution like a university needs to counter this deepening trend. That idea is not questioned in this essay. Yet it is mistaken to presume that the pursuit of equality in individual universities pre-dates the 20th century and is therefore an inherent and defining function. During their thousand-year evolution out of the Middle Ages, universities have served the stability needs of empires and nation states in spheres like law, administration, politics, religion, the economy and culture. This was so for most of their history, but it is erroneous to pretend that combating inequality was also a function they purposely performed in the centuries before the last 100 years.

Here I concentrate on what is pertinent to our South African universities in their struggle to meet so many demands, certain of which appear mutually contradictory. To do that it is necessary to examine universities as institutions that function in specific ways in the world and, in particular, the relationship in which universities stand to the larger society as unique institutions.

First, all the universities in the world that merit the label are elitist in their culture and practice. A more neutral term might be selective but, in general, universities admit only students who are judged to have the intellectual abilities needed for academic success. Of course it is the case that many, probably most, universities have programmes of inclusion for high-school graduates from poor families and unpromising cultural backgrounds in recognition of the abilities of such potential students.

A sub-group are research universities by name because the internal allocation of activities within them places a higher priority on research compared to the average tertiary institution that exists within their national education 
systems. Courting potential confusion, in the USA these are also known as 'public research universities', despite many being privately founded and partially funded. They are public because they receive a portion of their financing from federal, state and local appropriations.

Research is accorded much more attention at present than in the past for historical reasons. This was the case in particular before the rise to international prominence of organised research in German universities in the 19th century. Other universities, the majority in the world today, attempt to mix teaching and research activities in ways judged best to meet their national priorities as they interpret, or sometimes are set, for post-school education. They recognise that teaching and learning at this level are for the most part the assimilation of what is already known.

This mixture of institutional types is the case in South Africa, as in numerous other countries and most notably in Latin America and Africa. Such differentiation or diversity can complicate fulfilment of the functions adopted by the institutions themselves on the one hand, and those functions imposed on them by government or founding donors on the other.

The first modern university, Bologna, was founded in 1088 to train theologians, administrators, lawyers, literary scholars and scientists, mainly mathematicians and astronomers. Today theologians are not prominent, but scientists and applied scientists as well as engineers and humanities scholars are categories of intellectual skill produced uniformly in almost every recognised university in the world.

The thorny question all such institutions face is whether excellence is complemented or is challenged by the pursuit of equity? It is not possible to generalise, so the question is best left open and not, as in South African policy discussion, simply presumed to be the joint goals of every university and that are never in conflict.

It is important not to confuse the exclusivity argued here to be intrinsic and essential for every university as a historically evolved institution, with the elitism of enrolment that can be contrived by particular universities for their own motives. These motives are usually financial. For example, Ivy League universities in the USA keep their undergraduate numbers down because this raises the value of, and therefore the price to be paid for, a place at Harvard, Yale or Princeton or at the other institutions with similar goals within that exclusive grouping. So their first degree enrolments are limited to 5000-6000. Postgraduate totals are more flexible because they determine research output, institutional research status, and the ultimate pull on research funding.

Thus a place at Harvard is what in economic terms is called a positional good. It is prized highly because it is unique and scarce. A larger supply would bring the value down. A useful metaphor for understanding this concept is that of a crowd attending a popular event. If one person stands on tip-toe then he or she sees more and further than everyone else; but if every person in the crowd stands on tip-toe then no one sees anything. ${ }^{1}$ Access to such a good is contrived and controlled by the suppliers. At a university it leads to a deliberate form of individual elitism that is neither discussed nor advocated in this essay.

Second, academics see themselves as members of an international community. This is true of all national universities but is strongest in traditional English-language institutions because of the worldwide predominance of English in science and many other kinds of scholarship. Research and teaching objectives drive academic staff backwards and forwards between countries. For example, at present $41 \%$ of academic staff at Oxford University in the United Kingdom are non-British nationals.

One of the telling criteria of membership in this worldwide academic community is the consciousness of standards that come from abroad, and the necessity of measuring up to these standards. Seldom written down, but a powerful criterion of success, is the presumption by many South African universities that their best graduates at honours level, after 4 years, are usually accepted for postgraduate study by the major universities of the world. If this should stop being the case, then local academic staff will detect a serious decline in the academic standing of their institutions.
Third, changing the culture of universities is difficult and time-consuming for legislation and dedicated policies to achieve when judged necessary. A simple definition will meet the present purpose:

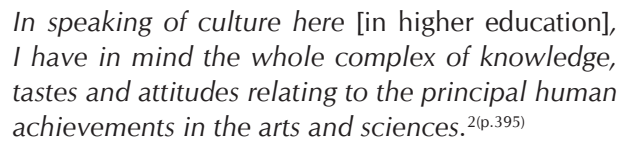

Fourth, autonomy is essential for open-ended and freely chosen research and teaching activities. This means self-recruitment, ${ }^{3}$ independent admissions policies, the complete absence of ideological influence, whether religious or political, and above all no direction from the organs of the state. The 20th century included a number of clear examples of the destructive effect of state domination of universities, like the Lysenko aberration in plant genetics research in the USSR under Stalin, and the nationalist infection of German physics and chemistry under Hitler. Ironically, this isolation probably set back progress on German development of atomic weaponry. More generally, state domination of once autonomous institutions like universities was completely orthodox policy under the Leninist interpretation of socialism that came to be called Communism between 1918 and $1989 .{ }^{4}$ Contemporary Venezuela appears to be another example of destructive state meddling in the governance of universities, given the news of a large-scale exodus by academics under Hugo Chavez's policies that have led to curricular interference, reduced university funding, inadequate salaries and a high crime rate. ${ }^{5}$

\section{First-order and second-order functions}

The functions just listed are the characteristics that define a good university wherever it may be. Numerous other requirements exist, but for a perspective on South African universities at the present time, these four characteristics are the important determinants of their functioning that have to be preserved in any process of reform.

Why are these specific features considered essential for the roles that a university plays in a constitutional democracy? Because on the basis of historical experience they make up the only inherent source for the sets of attitudes, skills and aptitudes required to provide stability in a nation state. When institutionalised these practices comprise democratic government, the sustaining of a cultural life satisfying to all classes, and the emergence and promotion of a self-sustaining economy. More broadly conceived, the material welfare levels of a national population are stabilised most effectively under such economic arrangements.

The group providing these skills and abilities sometimes is called a meritocracy, and this label should be a matter of taste rather than of polemic when we try to understand what is dispensable and what is not in the functioning of a university. Our present South African dilemma in policy formulation is how far universities' demand for intellectual talent to meet their defining obligations should be compromised in the pursuit of redress for past apartheid practices. During the time of what has been called 'high apartheid' in particular, the state's discrimination against and neglect of tertiary education provided for black citizens is not at all in dispute in this Commentary but, in fact, supports its arguments.

Viewed in this way, the present contention is that we cannot presume on grounds of political expediency that institutional policies aimed at the remedial admission of large numbers of underprepared students, and the preferential employment of staff self-identified as black, will not hinder the maintenance of a meritocracy. A higher education system performing in accordance with international standards, whether characterised as meritocratic or not, is essential to counter the emergence of a South African fragile state in the future.

To assume there is no conflict between the defining features of a university, and the imposition on it of second-order goals is certainly risky. That is, as already stated, in the South African case, to pursue redress through the imposition of redistributive and 'developmental' tasks, is not prudent in the absence of much more policy research. At present such actions fly in the face of the risks of failure and the unknown probability that governs negative consequences for universities. The simple point is that nobody knows. 
Yet this assumption of no conflict between a university's functions appears to be dominant in the minds of South African politicians, civil servants, certain educationists, and, not surprisingly, student groups. The latter in particular have not considered seriously the possibility of threats to the integrity of their institutions. One purpose of this essay is to bring into the open the possible costs which, in the broad sense of socially created obstacles, will have to be paid for institutional failure.

To be clear, there is no doubt that what is being pursued and what has been achieved by individual South African universities under the heading of 'overcoming the secondary-tertiary [level] articulation gap' is commendable and must be supported by any protagonist in the policy arena of tertiary education. ${ }^{6}$ Such policies of redress are certainly not being questioned in this paper. But what should be examined are the assumptions underlying these programmes. For instance, are there or will there be a sufficient number of individual lecturers interested in pursuing careers in the way of 'professional development of academic staff [engaged in these programmes]... and the growing support for the scholarship of teaching and learning' of students underprepared by academic criteria, as some observers contend is already the case in a number of South African universities? ?(p.112)

It must also be recognised that student success in these special programmes is mixed. This is partly because different disciplines, different remedial strategies, and different universities make generalisation a problem in assessing the accuracy of any encompassing statement. Their problematic performance goes much deeper of course. The following is one recently published example of disappointment with a well-designed set of remedial courses:

\begin{abstract}
The key finding of the current study is that the educational interventions included in the firstyear courses in the $A D$ [academic development] programmes in commerce, engineering and science [faculties] did not have a statistically significant effect on the graduation rate achieved by $A D$ students for the period under investigation. These findings carry weight as each of the three programmes was configured differently at the time and the econometric results are consistent with each other. The findings are disappointing given the substantial effort and resources into improving $A D$ students' academic performance during the years covered in the study [at UCT]..$^{8(p .635)}$
\end{abstract}

As our universities are now constituted, and to the extent to which certain of them aspire to be research institutions on the international model, such a presumption, about greater numbers of academic staff building their careers on higher education development, is questionable. This presumption remains to be researched with the necessary thoroughness.

Yet this field should be seen as comprising work that is pioneering on an international scale. Its success or failure will convey forceful lessons for universities elsewhere in the world that are attempting, more resolutely than at any time in the past, to pursue both the goals of efficiency and equity at the same time. Awareness of inequality in wider society is on the increase, as is the recognition that wider access to all forms of tertiary education is an essential component of the needed remedy.

\section{Historical precedents}

A look at history clarifies the functions that universities play today. After the first founding at Bologna, late medieval universities appeared throughout Europe and were driven by the renewed interest in Roman Law, in particular the Code of Justinian dating from 529 and formulated first in Constantinople. Both the church and the emerging states or principalities making up the units of government came to value the sophistication of Roman Law in the promotion and regulation of contracts and in administering the evolving market economy.

The renewed emphasis on the concepts of social order and justice, and their operational interpretation in daily life when viewed through the lens of Roman legal thinking, led to state administration and commercial relationships becoming systematised and institutionalised. These innovations had multiple goals in the early modern states. They aimed to place limitations on the power of political rulers; to establish the authority of law in its capacity to constrain and control the behaviour of public officials and private authority figures; to make rights to private property more secure; and to provide 'mechanisms for contract enforcement, and facilitated coordination among powers', in the political as well as economic spheres of the political units destined to become the nations of Europe. ${ }^{9}$ Most of these states emerged 'out of the German lands of the Holy Roman Empire's.

Driven by the emerging demand, university training in law and state administration took their places as taught disciplines alongside theology, philosophy and science, mainly in the shape of mathematics and astronomy. Universities and their students were granted privileges because of their role in stabilising the new states. They provided unique supporting institutions, recognised in time as such by rulers and administrators who held political power.

These inherited functions exist today in most if not all the world's universities worthy of the name. They exist in particular in research universities, whether these universities are mature or aspiring to that function and status. As already explained, all universities aim to produce the skills and aptitudes essential for providing administrative, cultural and economic services without which a state would fail or at least become fragile, threatening failure as recent examples show. ${ }^{10}$ In the economic sphere, these skills are those without which the use of sophisticated technology in production is not possible.

What is disturbing in South Africa is that certain politicians and bureaucrats, as well as educationists, are determined to 'transform' existing universities by making their racial profiles of staff and students 'demographically representative'. It is disturbing because the wider and deeper potential consequences have not been investigated in the discussion arena.

So the existing policy interpretation of this reform is not backed by thorough and objective research. Evidence in support of this judgement is provided by the recent actions of the Minister of Higher Education and Training, Dr Blade Nzimande. In 2013, he set up an oversight committee on university transformation headed by Prof. Makgoba, Vice-Chancellor of the University of KwaZulu-Natal. In their turn, Prof. Makgoba and a colleague, Dr Govinder, in 2015 devised an 'Equity Index' to measure so-called 'transformation' when it is applied as a standard to individual universities. Not surprisingly, this index has been severely criticised, not only on ethical and political grounds but for its technical failings as a measuring device. The debate about its purpose and acceptability can be followed in recent issues of the South African Journal of Science. ${ }^{11-15}$

\section{Individual benefits and external effects}

As stated, the present Commentary aims to provide an historical as well as an international perspective on this set of issues. In this way it should inform the local discussion that appears increasingly fixated on a single issue, namely that South African universities are trying to compensate by policies of remediation for their apartheid past as best they can, with little analytical guidance. For instance, prominent research universities in Western Europe and America, like the Ivy League, Oxbridge, the Sorbonne and numerous others, have been heavily criticised as unsuitable models by certain South African educationists. Their sets of values and ideas are judged unwelcome as precedents to be followed by the universities of developing countries including South Africa. This case is argued in particular when tertiary education redress is in question, and it tends to be approached as the overriding objective of South African university reform. Representative instances of this negative viewpoint on elitism are not hard to find. ${ }^{16}$

This criticism is questionable on a number of grounds. First, elitism, interpreted as the recruitment of the best intellectual talent in a country, as already explained, is a defining feature of the vast majority of contemporary universities in the world that aim to fulfil their intended functions. Second, the pursuit of equity and social justice as second- 
order goals can be persuasively argued as not possible without the effective performance of those first-order functions already described. So, to achieve the re-distributive or social justice objectives demanded of South African universities in the political arena depends on the prior recruitment of a national elite within a democracy. This elite has to be deployed in every supporting institution of government, civil society and the mixed economy as discussed below. Third, it is a confusing source of bias to criticise and reject only the universities in older developed countries, as in Europe and America, to refer principally to those using mainly the English language, for being models that are judged too elitist for developing countries. This criticism is far from an accurate characterisation of the world's universities.

For instance, the major universities in Asian countries, such as Japan, Korea and Singapore, exhibit a degree of competitiveness in job appointments, selectivity of student enrolments, and the mobilisation of academic resources that is at least as high as that found in research universities elsewhere.

Yet it is important to be aware that causation is likely to run both ways. The recruited elite make for nationwide political stability, for a rewarding culture and society, and for steady economic growth. Yet success in these spheres, marked by the high status and monetary rewards paid to these elite graduates, in turn encourages and makes possible the university production of the talents and skills that are considered essential ingredients in such national elites.

In addition, it is vital to recognise the external effects, which are benefits for the wider society that do not accrue only to the successful individual graduate, but which emerge freely available from well-functioning universities. The most important categories of these external benefits can be characterised as philosophical understanding, generalised trust towards others and moral imagination.

Of course it is perfectly possible to acquire skills in philosophy and the other dimensions, and to use these skills in multiple ways outside a formal institutional environment like a university. But in the contemporary world all serious study of these subjects takes place in universities. It is there that disciplined thinking is taught deliberately, both for applied purposes like reforming the law, formulating state policies in every domain, and enriching the forms of culture, and yet also for the wider perspective on human life that makes philosophical understanding so vitally important. Bertrand Russell was admirably clear:

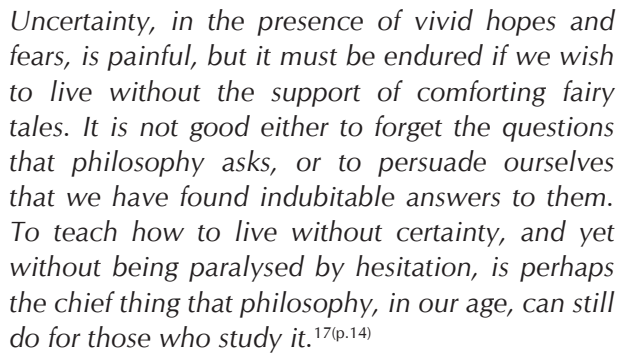

The further tasks of universities, best classified as cultural, are to build the institutions that foster generalised trust in all individuals towards others, as well as their moral imagination. Within every society, the absence of such trust is a major source of arrested social and economic development. Credibility, or the capacity of being believed by others, for instance, is the precondition for retaining trust and legitimacy.

There is no easily understood causal model that links universities with the existence of generalised trust and moral imagination in society. The intermediary institutions tend to be diffuse. So the evidence is indicative more than definitive. Here too there is the likelihood of reverse causation: the presence of trust and moral imagination within a population, brought into being by other causes, fosters the foundation of institutions like universities.

Sometimes such trust at a collective scale is measured by what is called social capital, the term coined by Putnam and currently growing in use although not universally popular. It means valuable knowledge and skills that are bestowed by a set of institutions that have come and some that have gone in the course of history. An example is the guilds which dominated economic life in the Middle Ages, comprising the precapitalist system then conceived and known as a moral economy. Its principal linkages between individuals were moral obligation not social relations mediated through market processes. The concept underlying such social capital is simple enough even when identification and measurement is not so in practice: 'Those persistent and shared beliefs and values that help a group overcome the free rider problem in the pursuit of socially valuable activities. ${ }^{18(p .6)}$

How do universities produce and sustain generalised trust? They do so through the construction and maintained stability of institutions without which trust cannot exist. Clear instances are the supportive underpinning of contract law essential for collaboration between individuals and groups; an efficient law enforcement system that evokes legitimacy; political institutions that encapsulate democracy, and thus engender active support and not rejection of the underlying moral values; constitutions that provide clear and unambiguous guidance to state policymakers, the political elite, and to the citizenry; civil society organisations that harness collective interests and efforts; formal institutions of education at all levels; and the regulation and control of the largest economic units, like corporations that generate profit for individual owners, as well as trade unions or federations that pursue the partisan interests of their members.

These are an illustration and not a complete listing. They suffice to demonstrate which institutions in society would not function or at best function imperfectly without the instruction, training and research activities of universities.

Trust is not recognised often enough, when insufficient, to be a major constraint on social cohesion, cultural deepening, and the economic development process. When attained, trust is thought of in practical terms as providing contractual assurance between people in the conduct of social and economic life. Thereby it governs the efficiency essential for economic progress. Yet this view can be too limited and potentially distorts a functional perspective necessary for universities. The differential development of nation states is a good example.

I have remarked on the responsibility for truthfulness in economic life, but the issue goes even further. Virtually every commercial transaction has within itself an element of trust, certainly any transaction conducted over a period of time. It can be plausibly argued that much of the economic backwardness in the world can be explained by the lack of mutual confidence. ${ }^{19(0.356-357)}$

One final illustration of a university function concerns moral imagination. This is the quality in an individual which makes human life not only endurable for that person but enriches the lives of others, who together make up the collective entities or groups that constitute any given society. When this moral dimension of the individual personality is weak at the aggregate level - that is, the entire population that is living together - we suffer the consequences of a fragile state or, in the extreme, a failed state. The current migration crisis experienced not only in South Africa but also in Europe is a clear consequence of the numerous failed states to our north and further south and east of Europe.

The Treaty of Westphalia in 1648 marked the end of Europe's Thirty Years War. By so doing, it also inaugurated the nation state as the basic unit of political order that has survived much conflict between states in the succeeding three and a half centuries.

From the mass of overlapping rulers - emperors, kings, dukes, popes, archbishops, guilds, cities, etc. - the Peace of Westphalia produced a solution of dazzling simplicity and longevity. The governing unit henceforth would be the state. Borders would be clearly defined and what went on inside those borders (especially the choice of religion) would be decided by its ruler and a matter of no one 
else's business. In modern terms, the delegates invented and codified state sovereignty, a single authority governing each territory and representing it outside its borders, no authority above states, and no outside interference in states' domestic affairs... [Yet today the growing] limits on global resources, porous borders, a globalizing culture... cannot be seen only as a matter of the distribution of state power...The Westphalian order is not going away, but it is no longer what it once was. It's too soon to see what that system and the new [non-state] forces will produce as they co-exist; but it's safe to say it won't look anything like the familiar past. ${ }^{20(p .5)}$

So at the present time there is speculation and concern that certain existing states show vulnerability due to the incompleteness as well as recent decay of their democratic institutions. It is too early to say whether the rise of religion in the post-colonial era, associated with 'authoritarian resurgence or democratic backsliding', will destroy states. Though the prospect remains troubling. ${ }^{21-25}$

To foster the moral imagination of individuals is a social task performed by institutions, many created essentially through university teaching and research practice. This claim is not that universities pursue and achieve this directly; and such a process of moral imagining is not exclusive to universities of course, but they are prime movers.

Without such a contribution by education at the tertiary level, it is difficult to imagine such institutions coming into being to sustain a tolerant and humane order. Historically, this order has come about by natural evolution as well as by purposive administrative practice devised for its achievement. It is accepted by scholars that such a trend characterised the history of the contemporary university, commencing immediately after its European foundation in Bologna. ${ }^{3,26,27}$

The institutions required to avoid social conflict range from the mundane to the essential. Clear examples are the political and administrative complexes of a modern state that demand high levels of collective order absent before the emergence of such states; effective political processes that reflect the majority values and views of citizens; institutions that foster tolerance and respect for those who are different; taxing authorities that are considered legitimate and support voluntary compliance without which they would not work; and thus steady revenue and expenditure flows at nationwide level that are governed by appropriately skilled and honest officials.

In addition, there is the administration of the stabilising activities that only the state can undertake nationwide (or, ironically, destroy) with its monopoly of authority, power and the pressure it can apply for compliance by individuals. Again, simple instances are the required immunisation of children against selected and specified diseases; their compulsory early education; and the complete education of all citizens up to some level decided to be individually and socially desirable by the political process.

At their widest, these are examples of the institutions which govern the ever-changing character of attitude, aptitude and the formation of skills in all human beings. This is so from the chosen perspective in this essay, specifically at the post-school level that comprises all the forms of education and training taking place in a given state.

Moral imagination does not yet constitute a set of issues amenable to research at the aggregate or society-wide level. Although in the perspective given in this paper, it is certainly plausible that tertiary education is a key influence in the emergence of the kind of imagination that generates social morality. This is essential for cooperation amongst a large number of individuals in groups who share interaction as well as resources but do not relate inter-personally. That is, one can infer confidently that these are aggregations of people sufficiently large to produce and support institutions that create cooperation and stability.
Whether when viewed this way, universities should be accorded status as the culminating institutions in the chain of human development phases that begin with the role of the family remains an open question. A recent strand of research work has emphasised this perception of inter-connected stages because it has far-reaching implications for the strategic direction and sequencing of national education, training and all other policies aimed at enhancing human ability. This is clearly of considerable pertinence in current South Africa. Prominent researchers in this field describe the underlying hypothesis in the following terms:
The recent literature is based on multiple generation models with multiple periods of childhood and adulthood. It emphasises the dynamics of skill formation. Central to the literature are the concepts of complementarity, dynamic complementarity, multiplicity of skills and critical and sensitive periods for different skills. These concepts account for a variety of empirical regularities that describe the process of human development. Family environments during the early years and parenting are critical determinants of human development because they shape the lifetime skill base. Through dynamic complementarity they enhance the productivity of downstream investments [in skill and aptitude acquisition]....Later stage remedial interventions are generally less effective... ${ }^{28(p .57)}$

More simply put, such acquisition in its widest conception is cumulative. Success at the early stages of life, soon after birth, makes success at subsequent levels easier and more probable. Further, it has proved to be cheaper than later remediation in time and resource use. Catching up the skills missed in early life is possible but frequently inefficient and costly to the individual and to society. But this is not to say it is a set of actions that can be judged dispensable or avoidable in the real world. In certain situations brought about by historical circumstances, such policies are essential, as in current South African universities.

In the past, as well as in more recent times, the social role played by the moral imagination can be seen most clearly in the institutions of the welfare state. These evolved during the 20th century, gathering momentum after each major war. ${ }^{29-32}$

Part 2 of this Commentary will appear in a forthcoming issue.

\section{Acknowledgements}

I am indebted to the following individuals for making comments and suggestions about an earlier version of this article: Andre du Toit, Pamela Reynolds, Michael Rice, Michael Savage, David Welsh and Nicola Westcott. I wish to acknowledge ongoing research support from the South African Labour and Development Research Unit in the School of Economics at UCT.

\section{References}

1. Hirsch F. Social limits to growth. London: Routledge/Kegan Paul; 1977. https://doi.org/10.1016/S0313-5926(77)50008-2

2. Olafson F. Democracy, 'high culture', and the universities. Philos Public Aff. 1973;2(4):385-406.

3. Collini S. What are universities for? London: Penguin Books; 2012.

4. Appelbaum $A$. The Leninist roots of civil society repression. J Democr 2015;26(4):21-27. https://doi.org/10.1353/jod.2015.0068

5. Carmona A. Poor conditions blamed for Venezuelan scientist exodus. University World News [serial on the Internet]. 2014 July 18 [cited 2016 Dec 15]. Available from: http://www.universityworldnews.com/article. php?story $=20140717180605819$

6. Council on Higher Education (CHE). A proposal for undergraduate curriculum reform in South Africa: The case for a flexible curriculum structure Pretoria: CHE; 2013. Available from: http://www.che.ac.za/sites/default/files/ publications/Full Report.pdf 
7. Lewin T, Mawoyo M. Student access and success: Issues and interventions in South African universities. Cape Town: Inyathelo: The South African Institute for Advancement; 2014. Available from: http://kresge.org/library/studentaccess-and-success-issues-and-interventions-south-african-universities

8. Smith L, Case J, Van Walbeek C. Assessing the effectiveness of academic development programmes: A statistical analysis of graduation rates across three programmes. S Afr J High Educ. 2014;28(2):624-638.

9. Cantoni D, Yuchtman N. The political economy of educational content and development: Lessons from history. J Develop Econ. 2013;104:233-244. https://doi.org/10.1016/j.jdeveco.2013.04.004

10. Collier P. Fragile African states: What should donors do? FERDI Working Paper 95 [document on the Internet]. c2014 [cited 2016 Dec 15]. Available from: http://www.ferdi.fr/sites/www.ferdi.fr/files/publication/fichiers/wp95_collier_ web.pdf

11. Borden VH. Anything but simple: Inappropriate use of Euclidean distance in Govinder et al. (2013). S Afr J Sci. 2014;110(5/6), Art. \#a0065, 4 pages. https://doi.org/10.1590/sajs.2014/a0065

12. Cloete N. A new look at demographic transformation: Comments on Govinder et al. (2013). S Afr J Sci. 2014;110(1/2), Art. \#a0048, 4 pages. https://doi. org/10.1590/sajs.2014/a0048

13. Dunne T. Mathematical errors, smoke and mirrors in pursuit of an illusion: Comments on Govinder et al. (2013). S Afr J Sci. 2014;110(1/2), Art. \#a0047, 6 pages. https://doi.org/10.1590/sajs.2014/a0047

14. Govinder KS, Zondo NP, Makgoba MW. Taking the transformation discourse forward: A response to Cloete, Dunne and Moultrie and Dorrington. S Afr J Sci. 2014;110(3/4), Art. \#a0060, 8 pages. https://doi.org/10.1590/ sajs.2014/a0060

15. Moultrie T, Dorrington R. Flaws in the approach and application of the Equity Index: Comments on Govinder et al. (2013). S Afr J Sci. 2014;110(1/2), Art. \#a0049, 5 pages. https://doi.org/10.1590/sajs.2014/a0049

16. Jansen JD. Wrest power from English tyranny. Mail and Guardian [serial on the Internet]. 2013 0ct 04 [cited 2016 Dec 15]. Available from: http://mg.co. za/article/2013-10-04-wrest-power-from-english-tyranny

17. Russell B. History of Western philosophy. London: Allen \& Unwin; 1946.

18. Alesina A, Giuliano P. Culture and institutions. NBER Working Paper 19750 Cambridge, MA: National Bureau of Economic Research; 2013. https://doi. org/10.3386/w19750
19. Arrow K. Gifts and exchanges. Philos Public Aff. 1972;1(4):343-362.

20. Mathews JT. The road from Westphalia. New York Review of Books [document on the Internet]. 2015 March 19 [cited 2016 Dec 15]. Available from: http:// www.nybooks.com/articles/2015/03/19/road-from-westphalia/

21. Bermeo N. On democratic backsliding. J Democr. 2016;27(1):5-19. https:// doi.org/10.1353/jod.2016.0012

22. Fukuyama F. Why is democracy performing so poorly? J Democr. 2015;26(1):11-20. https://doi.org/10.1353/jod.2015.0017

23. Krastev I. Liberalism's failure to deliver. J Democr. 2016;27(1):35-38. https:// doi.org/10.1353/jod.2016.0001

24. Plattner M. Is democracy in decline? J Democr. 2015;26(1):5-10. https://doi. org/10.1353/jod.2015.0014

25. Walker C. The authoritarian resurgence. J Democr. 2015;26(2):21. https:// doi.org/10.1353/jod.2015.0025

26. Kagan D. Ave atque vale [Hail and farewell]. New Criterion. 2013;31(10):4. Latin.

27. Ogilvie S, Carus A. Institutions and economic growth in historical perspective: Part 2. CESifo Working Paper 4862 [document on the Internet]. c2014 [cited 2016 Dec 15]. Available from: http://papers.ssrn.com/sol3/papers. cfm?abstract_id $=2463601$

28. Heckman JJ, Mosso S. The economics of human development and social mobility. NBER Working Paper 19925. Cambridge, MA: National Bureau of Economic Research; 2014. https://doi.org/10.3386/w19925

29. Archer S. The basic homework on basic income grants in South Africa [document on the Internet]. CSSR Working Paper 122. Cape Town: Centre for Social Science Research, University of Cape Town; 2007. Available from: http://www.cssr.uct.ac.za/sites/cssr.uct.ac.za/files/pubs/WP122.pdf

30. Castles F, Leibfried S, Lewis J, Obinger H, Pierson C, editors. The Oxford handbook of the welfare state. Oxford: Oxford University Press; 2010. https:// doi.org/10.1093/0xfordhb/9780199579396.001.0001

31. Goodin R, Headey B, Muffels R, Dirken H-J. The real worlds of welfare capitalism. Cambridge: Cambridge University Press; 1999. https://doi. org/10.1017/CB09780511490927

32. Greve B. The Routledge handbook of the welfare state. Abingdon: Routledge; 2013. 